\section{ON A \\ NEW METHOD OF VERSION IN ABNORMAL LABOUR.}

By J. BRAXTON HICKS, M.D., F.L.S., \&c., assistant PHYSICIAN-ACCOVCHEUR AT GUY's HOSPITAL, AND PHYSICTAN
TO THE ROYAI MATERNIT CHARITY.

(Concluded from page 30.)

CASE 1.-Mrs. B-, of Walworth, a delicate, feeble woman, the mother of six children, about thirty-eight years old, and eight months advanced in pregnancy. For the four previous days she had been losing blood in gushes. Her attendant requesting me to see her, I found her, on my arrival, very blanched, pulse thready, very weak, and quick; voice very feeble; altogether in an exceedingly low state from flooding. The os uteri was about the size of a crown-piece, thickened, irregular, and unyielding; the placenta presenting three parts across it; the membranes not broken; no pains had appeared; fotus alive; movements feeble and convulsive; head presenting. Blood was still oozing. I, therefore, gave her plentifully of spirits and water; and introducing my hand into the vagina, I endeavoured to gently dilate the os. After trying some time, with very little effect, I thought it would be a great advantage if I could turn without entering the uterus, and put in practice the method previously described. The head receded to the left side as the breech came down. The shoulders then presented; but in a minute more they followed the head, and then the leg was easily felt through the membranes. Having broken them, I drew the knee into the vagina, and, plugging the os with the leg and breech, and keeping up a slight traction, I waited to allow rallying further. I also gave a dose of secale, with stimulants, to ensure contraction subsequently. As the os expanded, I gently drew down the fœetus, which was fully born (but dead) in about three quarters of an hour. She did not lose half an ounce of blood during the whole process, nor during the removal of the placenta, which was slightly attached, but not adherent. Had she lost another gush, she must have died at the time. However, the quantity already lost had been too much; for, after lingering out three weeks of extreme exhaustion, she died.

CASE 2.-Mrs. — of Castle-street, Borough ; aged about thirty-five; thin, but tolerably healthy; eight months advanced in her eighth pregnancy. During the fortnight previous to my seeing her, she had lost blood by gushes and clots, at no time very severe; and about six hours before there was a small gush, with clots, and at the same time the liquor amnii escaped, but no pains followed. I found there was still some bleeding, though not extensive, with clots in the vagina. Her appearance had not been affected by the 1oss. The os had been dilated to half the full size, but now it was so excessively irritable, that upon the slightest touch of the finger it contracted so that only one and at the most two fingers could enter. 'The placenta was stretched two-thirds across it, posteriorly. It here seemed to me that if the leg and breech of the fretus could be made to form the plug, the patient would be secure. The only way possible, without much risk, was to endeavour to put in practice the method before described, which was easily done, though not quite so readily as in Case 1, in consequence of the irritability of the cervix; still it was effected, notwithstanding the escape of the waters, without any force or pain, and under circumstances which would have precluded entry of the whole hand. By means of two fingers in the os, I drew down the knee into the vagina; and Mr. Woodman (the senior obstetric clerk) having passed a loop of tape through the bend of the knee, I left the case in his charge, with instructions not to hurry the birth, but to keep up gentle traction, and to plug the cervix. In about three hours, the os relared and dilated to its full size, when the foetus was brought down. It had apparently been dead for a day or two. Not the slightest drop of blood was lost during the whole process of turning and extraction, and the woman recovered without a single bad symptom.

CASE 3.-Mrs. P__, a fine, healthy person, well made, who had always had rapid labours. At the time $I$ saw her, she was at full term of her seventh pregnancy. Having been seized twice within the previous month with a gush of blood (each time about half a pint), she was kept quiet. Twentyfour hours before I saw her, she had had the third gush, which had continued ever since. I saw more than a pint, and the nurse said she had lost altogether as much more. At the time of my visit, the face was not much blanched, nor was the pulse much affected. The os uteri was fully dilated, the placenta half-way over it; uterus perfectly inactive. The liquor amnii had escaped, but the fotal head was high up; no violent bleeding, but conslderable oozing. There can be no doubt that the older method of version would have been very practicable. Still, as every circumstance was favourable, I turned by the method previously recommended, and found it very easily and speedily managed. In about two minutes sooner than I expecter, the foot was in my hand, and drawing the leg through and the breech to the os uteri, I kept up a centle traction. No uterine action ensuing, secale was given. In a quarter of an hour pains appeared. After the breech had passed the cervix, finding the funis pulsating, I hastened the delivery, good pains assisting. The child, although not breathing when born, was soon recovered by artificial respiration. No hæmor rhage appeared during the operation or expulsion of the fotus. The placenta not being thrown off soon, and a little hæmorrhage appearing, it was removed, being rather firmly attached.

CASE 4.-Mrs. C- Borough, aged about twenty-eight, of strong constitution. At about three weeks to completion of full term of her fourth pregnancy. About three weeks before, she had been seized, after a fright, with sudden and severe flooding. This passed off till twelve hours before I was called to her, when she was taken with a sudden flooding, nearly equal to a chamber-vesselful, accompanied by faintings, which continued during the twelve hours before I saw her. I found her perfectly blanched; pulse very feeble; extremities cold; could still swallow, and had taken about half a pint of brandy. The os uteri was about the size of a five-shilling piece; the placenta protruding, apparently centrally attached, but on carefully searching I found a portion of it thinner at the posterior aspect, and, carrying the finger backwards, the mem. branes were reached, unbroken; the head presenting. Being anxious to have command of the labour, with as little shock as possible to the patient in her very low condition, I employed the method mentioned above, with so much ease and rapidity that in about one minute the foot was in the vagina. In this case the membranes were ruptured at the beginning of the version; this, however, made no difference to the accomplishment of it. Continuing to make a plug of the breech, I waited till the system had rallied by stimulants, and in order to allow the os to expand and the pains to come on. In about an hour and a half the pulse improved, and two doses of secale were given; about half an hour later, gentle traction being employed, the child was born dead. The placenta was expelled by natural efforts. No hæmorrhage occurred after I commenced version. She recovered satisfactorily.

CASE 5.-Mrs. - the mother of eight children, about eight months advanced in pregnancy, was taken in the nightseven hours before I saw her-with sudden flooding, which was estimated at more than two quarts. Four hours after she sent for her attendant, who found her with her extremities cold, blanched, and lying before the fire. From that time till I saw her she had been losing blood by continuous oozing, considered to be about half a pint. On my arrival, I found her blanched, pulse scarcely perceptible, voice strong, and considerable muscular power. The os was dilatable, about the size of a crownpiece, but had not been so more than an hour. The placenta came at that time only to the margin. It had before been felt over the os in part. The liquor amnii had escaped; no pains. As the oozing was still going on, I was anxious to secure a plug. I therefore directed and assisted Mr. Wadkins (the senior obstetric clerk) in performing version by the method above de. scribed, which was done in a few minutes. The moment the head rose into the iliac fossa, the shoulder presented, and then as instantly the foot was in the hand of the operator. During this time we gave largely of stimulants, and apparently the patient had still considerable power. By the weight of the arm traction was kept up against the cervix, and in about half an hour the child was born (but dead), without any hæmorrhage at all. The uterus contracted well, and the placenta came away naturally. Warmth and stimulants were employed; but the pulse began to flag still more, and the powers gradually failed, till, about an hour after, she died, rather suddenly. It seems to me that if the version had been performed as soon as the os was capable of admitting a finger, the draining of blood might possibly have been prevented. The quantity lost at first was not precisely known till after death, and, coupled with the muscular power and uterine pains, there did not seem. any justification for retarding delivery, as has been recommended in extreme exhanstion.

Wellington-street, London-bridae, Ju'y, 1860. 